University of Nebraska - Lincoln

DigitalCommons@University of Nebraska - Lincoln

Gordon Gallup Publications

Research Papers in Physics and Astronomy

December 1953

\title{
Free Energy and Entropy of Translation Tables
}

Paul W. Gilles

University of Kansas, Lawrence

Gordon A. Gallup

UNL,ggallup1@unl.edu

Follow this and additional works at: https://digitalcommons.unl.edu/physicsgallup

Part of the Physics Commons

Gilles, Paul W. and Gallup, Gordon A., "Free Energy and Entropy of Translation Tables" (1953). Gordon Gallup Publications. 33.

https://digitalcommons.unl.edu/physicsgallup/33

This Article is brought to you for free and open access by the Research Papers in Physics and Astronomy at DigitalCommons@University of Nebraska - Lincoln. It has been accepted for inclusion in Gordon Gallup Publications by an authorized administrator of DigitalCommons@University of Nebraska - Lincoln. 


\section{Free Energy and Entropy of Translation Tables}

PAUL W. GILLES and GORDON A. GALLUP

University of Kansas, Lawrence

In the statistical caculation of the thermodynamic properties of ideal gases the translational contribution is calculated from the Sackur-Tetrode equation,

$$
S=R \ln \frac{(2 \pi M k T)^{3 / 2}}{h^{3} N^{5 / 2}} V+5 / 2 R
$$

in which $S$ is the entropy of one mole of a gas of molecular weight $M$, at absolute temperature $\mathrm{T}$, and volume $\mathrm{V}$ expressed in cubic centimeters; $\mathrm{k}$ is Boltzmann's constant; $\mathrm{h}$ is Planck's constant; $\mathrm{N}$ is Avogadro's number; and $\mathrm{R}$ is the molal gas constant expressed in the same units as those desired for $\mathrm{S}$, usually cal $\mathrm{deg}^{-1} \mathrm{~mole}^{-1}$.

Separation of terms yields

$$
S=\frac{3}{2} R \ln M+\frac{3}{2} R \ln T+R \ln V+R \ln \frac{(2 \pi k)^{3 / 2}}{h^{3} N^{5 / 2}}+\frac{5}{2} R
$$

in which the last two terms are constants. Substitution for $V$ from the ideal gas law gives

$$
S=\frac{3}{2} R \ln M+\frac{5}{2} R \ln T-R \ln P+R \ln \frac{(2 \pi k)^{3 / 2}}{h^{3} N^{5 / 2}}+\frac{5}{2} R+R \ln R
$$

in which $\mathrm{P}$ is the pressure of gas, usually expressed in atmospheres. The last three terms are constants but the last one requires clarification. The first $\mathrm{R}$ in this last term is expressed, as above, in the units desired for $\mathrm{S}$, while the second one is expressed in units commensurate with the units used for $\mathrm{V}$ and $\mathrm{P}$, usually $\mathrm{cc}-\mathrm{atm} \mathrm{deg}^{-1} \mathrm{~mole}^{-1}$.

For ideal gases in their standard states, the pressure is one atm, and the entropy becomes

$$
S^{0}=\frac{3}{2} R \ln M+\frac{5}{2} R \ln T+R \ln \frac{(2 \pi k)^{3 / 2}}{h^{3} N^{5 / 2}}+\frac{5}{2} R+R \ln R
$$

Similarly the free energy function for translation is

$$
\begin{gathered}
-\frac{\mathrm{F}^{\circ}-\mathrm{H}_{\mathrm{O}}^{\circ}}{\mathrm{T}}=-\frac{\mathrm{H}^{\circ}-\mathrm{TS}^{\circ}-\mathrm{H}_{\mathrm{O}}^{\circ}}{\mathrm{T}}=\mathrm{S}^{\circ}-\frac{\mathrm{H}^{\circ}-\mathrm{H}_{\mathrm{O}}^{\circ}}{\mathrm{T}}=\mathrm{S}^{\circ}-\frac{5}{2} \mathrm{R} \\
=\frac{3}{2} \mathrm{R} \ln \mathrm{M}+\frac{5}{2} \mathrm{R} \ln \mathrm{T}+\mathrm{R} \ln \frac{(2 \pi k)^{3 / 2}}{\mathrm{~h}^{3} \mathrm{~N}^{5 / 2}}+\mathrm{R} \ln \mathrm{R} \\
{[465]}
\end{gathered}
$$


It is clear from equations (4) and (5) that the standard entropy and free energy fuction for translational motion of ideal gases depend only on the molecular weight of the gas and the temperature. To facilitate the frequently necessary calculation of these quantities, we have calculated and are presenting here the values at different temperatures of these functions apart from the molecular weight term.

Two sets of constants are currently in use: one advocated by Rossini, Johnston, Gucker, Pauling, and Vinal (1) based on the work of DuMond and Cohen ${ }^{(2)}$, and one proposed in 1947 by the National Bureau of Standards in its Selected Values of Chemical Thermodynamic Properties ${ }^{(3)}$. The value for gas constant, $R$, is the same in both sets. Table I summarizes the values of the constants in both sets.

TABLE I

\begin{tabular}{|c|c|c|}
\hline Constant & NBS (1947) & $\underline{R}, J, G, P$, and $\vee(1952)$ \\
\hline$\left.R(c a) \operatorname{deg}^{-1} \mathrm{~mole}^{-1}\right)$ & $1.98719 \pm 0.00008$ & $1.98719=0.00008$ \\
\hline$R\left(\mathrm{~cm}^{3} \mathrm{otm}\right.$ deg $\left.\mathrm{g}^{-1} \mathrm{~mole}^{-1}\right)$ & $820567 \div 0.0034$ & $82.0567: 00034$ \\
\hline$k$ (ergs deg $g^{-1}$ moleculele $)$ & $(138048 \pm 0.00050) \times 10^{-16}$ & $(1380257 * 0.000067) \times 10^{-16}$ \\
\hline$h(e r g-\sec )$ & $(6.6242 \div 0.0044) \times 10^{-27}$ & $(6.62377 \div 0.00027) \times 10^{-27}$ \\
\hline$N$ (molecules mole $\left.{ }^{-1}\right)$ & $(6.02283=0.0022) \times 10^{23}$ & $(602380: 0.00016) \times 10^{23}$ \\
\hline$\frac{5}{2} R$ & $(4.96798 \div 0.00020)$ & $(496798 \div 000020)$ \\
\hline RInR & $875836 * 0.00044$ & $875836: 0.00044$ \\
\hline$R \ln \frac{(2 \pi k)^{3 / 2}}{h^{3} N^{3 / 2}}$ & $-160404_{2}=0.0045^{+}$ & $-1604132: 0.00072$ \\
\hline$R \ln \frac{(2 \pi k)^{3 / 2}}{h^{3} N^{5 / 2}}+\frac{5}{2} R$ & $-11.0724_{5}=0.0045^{t}$ & $-1107334: 0.00075^{-}$ \\
\hline$R \ln \frac{(2 \pi k)^{5 / 2}}{h^{3} N^{3 / 2}}+\frac{5}{2} A+R \ln R$ & $-23140_{9}=0.0045^{t}$ & $-231498 \div 0.00087$ \\
\hline$R \ln \frac{(2 \pi k)}{h^{3} N^{5 / 2}}+R \ln R$ & $-72820_{6}=0.0045^{+}$ & $-728296 \div 0.00084$ \\
\hline
\end{tabular}

The results of our calculations which are based on the later constants in Table I are given in Table II in which the first column gives the temperature in degrees $\mathrm{K}$; the second gives the free energy function without: the molecular weight term, $-\frac{\mathrm{F}^{\circ}-\mathrm{H}_{\mathrm{O}}^{\circ}}{\mathrm{T}}-\frac{3}{2} \mathrm{R} \operatorname{lnM}$ in cal $\mathrm{deg}^{-1}$ mole $^{-1}$; the third gives the entropy without the molecular weight term, $S^{\circ}-\frac{3}{2} R \ln M$ in the same units; and the last gives the differences between successive entries in the two preceding columns. The additive constants in the free energy function and entropy used in the preparation of these tables are taken, as Table I indicates, to be -7.2830 and -2.3150 respectively. It is clear from the probable errors listed in 
Table II. Translational Free Energy and Entropy Without Molecular Weight.

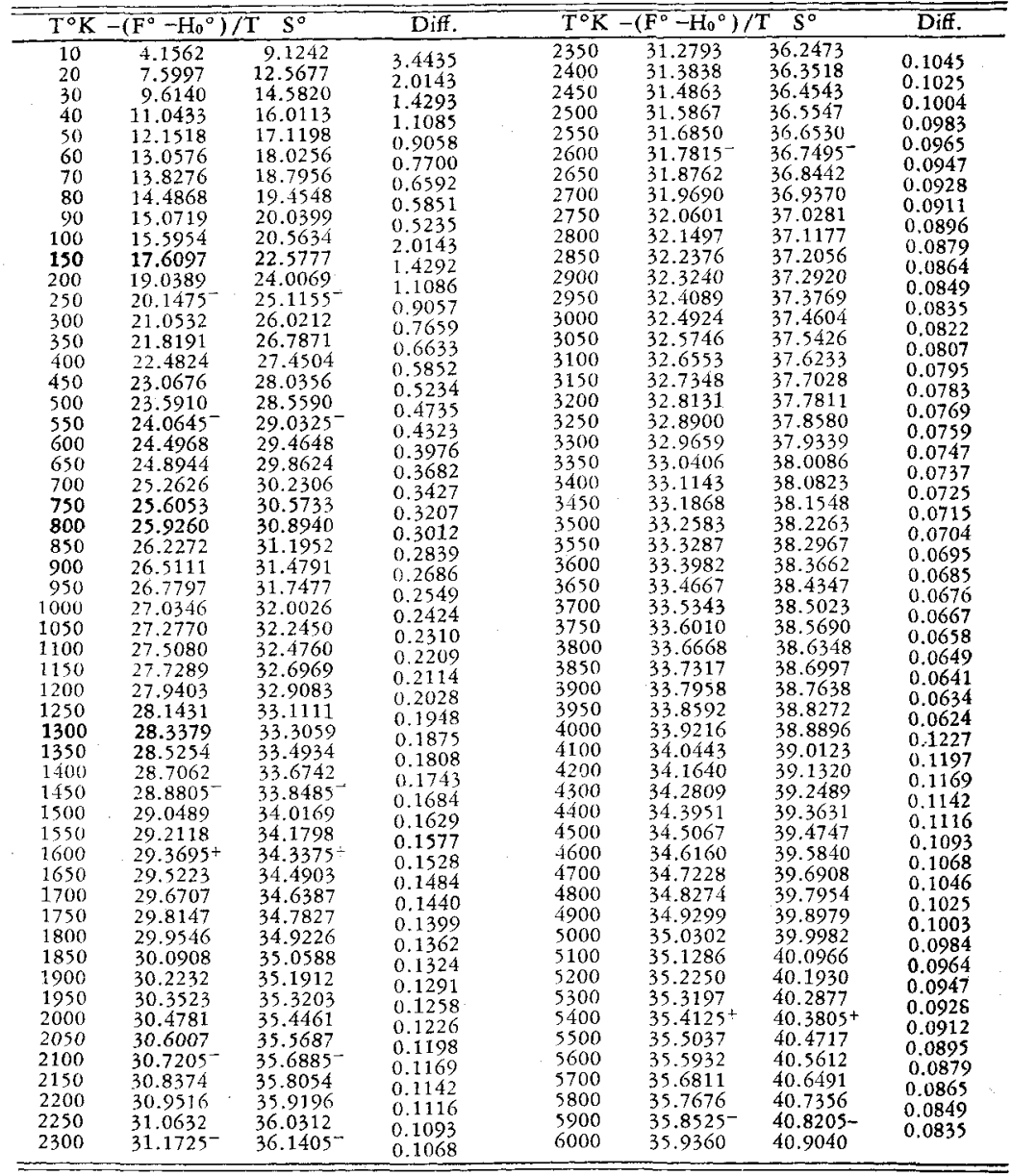

Table I that the values should have an accuracy slightly better than one unit in the third decimal place.

The free energy function and entropy of translation without the molecular weight term for $298.16^{\circ} \mathrm{K} .\left(25^{\circ} \mathrm{C}\right.$.) are 21.0227 and 25.9907 , respectively.

To obtain from the tables presented here values consistent with the NBS publications in which the additive constants have been taken as -7.2820 and -2.3141 , all the values in the second column should be increased by ten in the fourth decimal and all the values in the third column should be increased by nine in the fourth decimal. To be sure, 
little significance can be attached to this correction because of the large probable errors associated with the older constants.

The authors are pleased to acknowledge the support of the Atomic Energy Commission in this work. We wish to express our thanks to Mrs. Donna Sintz for checking the values in Table II.

1. Rossini, F. D., Johnston, H. L., Gucker, F. T., Pauling, L., and Vinal, G. W.; Jout. Am. Chem. Soc. 742699 (1952).

2. DuMond, J. W. M. and Cohen, E. R.; Phys. Rev. 82555 (1951).

3. Selected Values of Chemical Thermodynamic Properties NBS Circ. 500, Feb. 1, 1952, and loose leaf edition Dec. 31, 1947. 